matters ; while the Board of Trade is issuing an open general licence from the same date for the importation of compounds, preparations and articles, not suitable for use in dyeing, manufactured from synthetic organic dyestuffs. A joint committee of makers and users to consider prices and supplies will be set up by the trade early in 1934 .

\section{Charles Babbage, F.R.S.}

Aт a meeting of the Newcomen Society held at the Science Museum on December 13, Dr. L. H. D. Buxton read a paper on Charles Babbage and his difference engine, during which he gave a sketch of the career of Babbage, explained the design of the famous calculating machine, and exhibited many manuscripts and an unpublished biography of Babbage compiled by Dr. Buxton's grandfather. Babbage was born in Teignmouth on December 26, 1792, and died in London on October 18, 1871. He was educated privately and went to Cambridge in 1811. He joined Herschel and Peacock in forming the Analytical Society, graduated in 1814, and in 1816 was admitted a fellow of the Royal Society. He assisted in founding the Royal Astronomical Society and the Statistical Society, and from 1828 until 1839 was Lucasian professor at Cambridge. Possessing ample means, Babbage was able to follow his own inclinations, and among these was to construct a machine for calculating mathematical tables. This led him to the construction first of a difference engine, secondly to the construction of an analytical engine, and then of another difference engine. The relics of his machines, none of them ever finished, are in the Science Museum; his first difference engine was used by Dr. Buxton to explain Babbage's methods. Altogether Babbage spent some $£ 6,000$ of his own and some $£ 17,000$ allotted by the Government, on his first attempts, and then in 1842 the Government decided against any further expenditure. The failure of Babbage to bring to fruition his ideas was due to his constantly changing his mind, and being led off by some new scheme which promised better results, but which itself was only followed until a new idea arose.

\section{Electrical Equipment of London's Latest Hotel}

The Cumberland Hotel at Marble Arch, London, is now open to the public. It has a thousand bedrooms and the total number of lamps installed throughout the bedroom floors is nearly 10,000 , requiring 400 horse-power. The electrical installation work was carried out by the Electrical Department of Messrs. J. Lyons and Co., Ltd. The lighting is all done by the latest modern methods. In the octagonal lounge a continuous band of sun-ray tube encircles the room at ceiling level. It is partly hidden by a decorative cornice of amber glass rods. The drawing-room is lighted by eight inverted glass cone reflectors fitted in gilded recesses provided in the walls. In rooms with twin beds a somewhat novel switch is provided. It has two hinged doors. Should the occupant of the left-hand bed wish to read while the other sleeps, the light can be made to illuminate one side only by closing the other door. By closing both doors it becomes a night light which can be switched off if desired. The maid can be summoned by pressing a button; this lights a number of lamps which guide her to the room. The system for regulating the condition of the air in the rooms is very thorough. The air entering the building is passed through a huge air washer and dehumidifier which get rid of all impurity. It is then drawn through an oil filter and afterwards, if it is summer, it is cooled by refrigerators and, if winter, it is warmed by a bank of heaters. Guests can regulate the atmosphere of their bedrooms to three different levels by moving a valve lever. Throughout the public rooms are hundreds of concealed air inlets and also outlets which draw away used air, tobacco smoke, etc. The atmosphere is completely changed every four or five minutes. It is calculated that the fifty-four large fans move hundreds of tons of air hourly.

\section{Health Considerations in Motor-Car Design}

WE have received from Science Service interesting accounts of the meetings of the Society of Automotive Engineers held in Chicago during the past summer. Dr. F. A. Moss, of George Washington University, was of opinion that considerations of health would govern largely the design of motor-cars in the future. In particular he laid stress on the nature of the air inside the car, on the strain on the eyes of the driver and on his posture. Improvements in these respects will well repay the industry. The air condition inside the car should be thoroughly tested to find out the amount of carbon monoxide at various positions and also to measure the draught. In his opinion, control of the temperature and humidity inside a closed car would do much to improve the health of the occupants. Statistics prove that after a long journey accidents are more likely to occur. Dr. Moss attributes this mainly to eye strain. Tests with various types and makes of car show that prolonged driving leads to a great decrease in visual acuity, particularly after a distance of about 400 miles. Bodily posture, governed by seat design, is an important factor in the health and safety of the driver. No researches have been published on this point and it is worth investigating. Some attention might also be paid to the question of whether hard cushions or soft cushions are the best, and to the relative merits of cloth and leather upholstery.

\section{Pioneer Broadcasting in Norway}

ON February 23, 1933, Norway celebrated its tenth anniversary of radio broadcasting. An article by Mr. E. A. Brofus published in Radiobladet (Feb. 17) has been translated in the July issue of Electrical Communication, the journal of the Standard Electric Corporation. The author recalls that he erected in the office of the newspaper Nationen in Oslo in the early part of 1919 a small loudspeaker to broadcast the progress of the great skating race at Frogner to the people gathered in Karl Johansgate. A telephone line connected the skating rink to the newspaper office, but none of the amplifiers available 